\title{
No sweat: Favorable outcomes of hyperhidrosis surgery with age
}

\author{
Justin D. Blasberg, MD, ${ }^{a}$ and Benjamin J. Resio, $\mathrm{MD}^{\mathrm{b}}$
}

\author{
From the a Section of Thoracic Surgery, Department of Surgery, Yale New Haven Hospital, Yale University, New \\ Haven, Conn; and ${ }^{b}$ Department of Surgery, Yale New Haven Hospital, Yale University, New Haven, Conn. \\ Funded by the Section of Thoracic Surgery within the Department of Surgery at Yale New Haven Hospital. \\ Disclosures: Authors have nothing to disclose with regard to commercial support. \\ Received for publication July 17, 2018; accepted for publication July 21, 2018. \\ Address for reprints: Justin D. Blasberg, MD, Yale New Haven Hospital, 330 Cedar St, BB205, New Haven, CT \\ 06520 (E-mail: Justin.blasberg@yale.edu). \\ J Thorac Cardiovasc Surg 2018;156:1759-60 \\ $0022-5223 / \$ 36.00$ \\ Copyright (c) 2018 by The American Association for Thoracic Surgery \\ https://doi.org/10.1016/j.jtcvs.2018.07.055
}

The use of bilateral sympathectomy for the management of medically refractory craniofacial, axillary, and palmar hyperhidrosis is well established and associated with favorable outcomes. Recommendations to optimize the technical conduct of this operation, appropriate levels for division, and expected risk for compensatory hyperhidrosis have been described previously in great detail, including consensus guidelines published by the Society of Thoracic Surgeons in 2011. ${ }^{1,2}$ The long-term outcomes for endoscopic thoracic sympathectomy (ETS) vary but are generally excellent, particularly for patients with predominantly palmar symptoms. ${ }^{3}$ In most large modern series, patient satisfaction rates of $70 \%$ to $90 \%$ are reported. ${ }^{2}$ Additional benefits of ETS have also been described; in a recent study by $\mathrm{Li}$ and associates, ${ }^{4}$ the long-term use of psychotropic medication and rates of depression were significantly improved after surgical management of hyperhidrosis.

Although the data on ETS are robust, these recommendations are based on outcomes from single-institution data, small series, or meta-analysis of small series, which provide important but variable results on surgical success. Although these data are important and often used to help guide patient expectations, the risk of compensatory hyperhidrosis and quoted success of sympathectomy are often anecdotally derived rather than data driven. In addition, most patients who see a thoracic surgeon with medically refractory symptoms are young; the extent to which ETS is beneficial in older patients is presumed to be equivalent but is not well defined.

To that end, in this issue of the Journal, Leiderman and colleagues $^{5}$ have described their 14-year experience (including more than 1600 cases) with ETS for hyperhidrosis, deriving an expected yet important conclusion that favorable outcomes are achievable for most surgical patients and that success is independent of patient age. In their study, $90 \%$ of patients reported improvement in quality of life, with fewer than $6 \%$ reporting severe compensatory ously described.

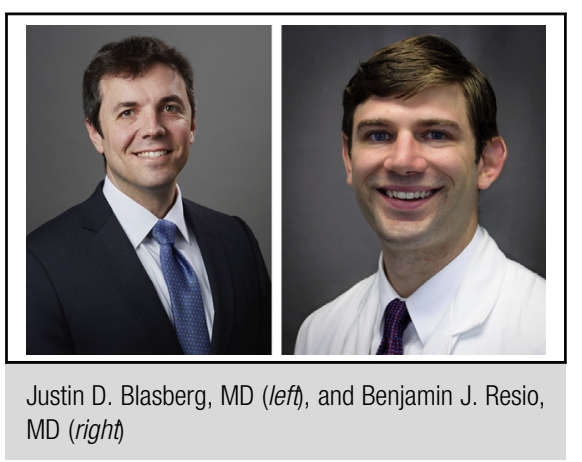

\section{Central Message}

Sympathectomy is effective treatment for medically refractory hyperhidrosis. Leiderman and coauthors describe a 14-year experience with more than 1600 patients to help guide clinical decision making.

See Article page 1748.

hyperhidrosis. Only $8 \%$ of patients had a postoperative complication develop (mostly pneumothorax), and fewer than $1.5 \%$ reported no improvement in symptoms after ETS. These results are consistent with other published surgical series and vary according to the level of the sympathetic chain disrupted. ${ }^{6-8}$ The features that set the study of Leiderman and colleagues ${ }^{5}$ apart from previous work are the large sample evaluated, the inclusion of a large number of older patients, and the robust follow-up data, which allow validation of many of the conclusions derived from older, smaller ETS studies. In addition, the degree to which Leiderman and colleagues ${ }^{5}$ evaluated the functional improvement achieved by surgery, including quantifiable methods to assess compensatory hyperhidrosis from patient questionnaires administered before and after ETS, provided unique insight into patient satisfaction metrics not previ-

This study of Leiderman and colleagues ${ }^{5}$ is methodologically sound, with conclusions that have significant clinical impact; however, there are some limitations worth mentioning. Leiderman and colleagues ${ }^{5}$ suggest that ETS can lead to favorable outcomes even as patient age increases; however, the age range of this study cohort is still quite young and narrow. The median age reported was just 25 years old, and the interquartile range was from 21 to 30 years old, which is consistent with most large 
single-institution series. Although this study contains one of the largest adult populations in the literature, there are still relatively few adult patients relative to childhood and adolescence groups. Caution should therefore be taken when extrapolating these results to older patients. In addition, it is encouraging that there were very few patients who had either compensatory hyperhidrosis or lack of improvement after surgery (73 and 24 patients, respectively). The small number of witnessed events limits the power in distinguishing whether age is truly an independent factor associated with outcome, however, and as such the provided multivariable model was not significant in this regard. Also of interest is the change in technical practice described; early in the study, sympathetic chain resection was performed; this was later replaced by thermoablation. Whether a particular ETS technique is superior remains debatable, however; outcomes are more likely related to the level of chain disruption rather than to technique. ${ }^{1}$ Each surgeon should choose a technique (clipping vs dividing, cautery vs energy device) that is most comfortable; knowing which levels to disrupt and to avoid injury to the stellate ganglion will result in similar rates of anhidrosis and patient satisfaction.

Although most patients with hyperhidrosis continue to have the condition managed medically, there is still clearly a role for sympathectomy to treat refractory symptoms. The durability of ETS appears to be independent of age; the presentation of patients with hyperhidrosis symptoms in their later years should therefore prompt a plan of evaluation and management with similar vigor as younger patients. Although techniques for sympathetic chain disruption vary, there is a general consensus that the risk for compensatory hyperhidrosis increases as the number of levels divided increases. The Society of Thoracic Surgeons consensus guidelines continue to be relevant as a clinical guide and are validated by this study and others. Future work to define the early use of ETS in patients at risk for medically refractory hyperhidrosis may fast track specific subgroups, including older patients, to this highly effective surgical procedure.

\section{References}

1. Cerfolio RJ, De Campos JR, Bryant AS, Connery CP, Miller DL, DeCamp MM, et al. The Society of Thoracic Surgeons expert consensus for the surgical treatment of hyperhidrosis. Ann Thorac Surg. 2011;91:1642-8.

2. Sternbach JM, DeCamp MM. Targeting the sympathetic chain for primary hyperhidrosis: an evidence-based review. Thorac Surg Clin. 2016;26:407-20.

3. Horslen LC, Wilshire CL, Louie BE, Vallières E. Long-term impact of endoscopic thoracic sympathectomy for primary palmar hyperhidrosis. Ann Thorac Surg. June 7, 2018 [Epub ahead of print].

4. Li DC, Hulbert A2, Waldbaum B, Ober C, Hooker CM, Huang P, et al. Endoscopic thoracic sympathectomy for primary focal hyperhidrosis: impact on psycho-social symptomatology and psychotropic medication use. Eur J Cardiothorac Surg. May 30, 2018 [Epub ahead of print].

5. Leiderman DB, de Campos JRM, Kauffman P, Tedde ML, Yazbek G, Teivelis MP, et al. The relation between age and outcomes of thoracic sympathectomy for hyperhidrosis: the older the better. J Thorac Cardiovasc Surg. 2018;156:1748-56.

6. Gossot D, Galetta D, Pascal A, Debrosse D, Caliandro R, Girard P, et al. Long-term results of endoscopic thoracic sympathectomy for upper limb hyperhidrosis. Ann Thorac Surg. 2003;75:1075-9.

7. Li X, Tu YR, Lin M, Lai FC, Chen JF, Dai ZJ. Endoscopic thoracic sympathectomy for palmar hyperhidrosis: a randomized control trial comparing T3 and T2-4 ablation. Ann Thorac Surg. 2008;85:1747-51.

8. Yazbek G, Wolosker N, Kauffman P, Campos JR, Puech-Leão P, Jatene FB. Twenty months of evolution following sympathectomy on patients with palmar hyperhidrosis: sympathectomy at the T3 level is better than at the T2 level. Clinics (Sao Paulo). 2009;64:743-9. 